\title{
Diagnosis and Management of Takotsubo Cardiomyopathy
}

\author{
Satoshi Kurisu and Yasuki Kihara
}

Key words: prognosis, complication, treatment

(Intern Med 54: 1-2, 2015)

(DOI: 10.2169/internalmedicine.54.3454)

Takotsubo cardiomyopathy is an acute cardiac syndrome that mimics acute myocardial infarction (AMI) (1-3). The initial presentation of both diseases is similar, usually including chest symptoms, electrocardiographic (ECG) changes and left ventricular apical wall motion abnormalities. AMI occurs predominantly in men, whereas Takotsubo cardiomyopathy occurs predominantly in elderly women. It is important to note that the ECG changes and apical wall motion abnormalities observed in patients with Takotsubo cardiomyopathy are not related to acute plaque rupture or myocardial ischemia associated with coronary atherosclerosis. In the clinical setting, Takotsubo cardiomyopathy is an important disease that must be differentiated from AMI for appropriate management. For example, thrombolytic therapy is useful for treating AMI; however, it is of no benefit in patients with Takotsubo cardiomyopathy.

In this issue of the Journal (4), Kamada et al. described a case of Takotsubo cardiomyopathy triggered by statininduced rhabdomyolysis. The patient was a man with atherosclerotic risk factors, including dyslipidemia, diabetes mellitus and peripheral artery disease. In that case, it was challenging to differentiate between AMI and Takotsubo cardiomyopathy noninvasively based on the patient's initial presentation. Kamada et al. pointed out that the detection of STsegment depression in lead aVR without ST-segment elevation in lead V1 was useful for making the diagnosis. The ECG findings were suggestive of Takotsubo cardiomyopathy, and coronary angiography was deferred at the time of admission to prevent the occurrence of any contrast-induced acute kidney injury. Coronary angiography was thereafter performed on the third hospital day to confirm the diagnosis.

As shown in this report, the diagnostic value of ECG for detecting Takotsubo cardiomyopathy is well established $(5,6)$. Recently, the predictive value of this modality has also been investigated. For example, cardiac rupture is a rare but life-threatening complication of Takotsubo cardiomyopathy $(7,8)$, and Kumar et al. showed that patients with cardiac rupture exhibit an older age, higher double product, increased frequency of persistent ST-segment elevation and reduced frequency of use of beta-blockers (7). In the current case, the patient's heart rate was approximately $140 \mathrm{bpm}$, and the level of ST-segment elevation on the initial ECG was unusual. Furthermore, the ST-segment elevation persisted until the third hospital day. It is noteworthy that these ECG findings are suggestive of a possible case of cardiac rupture. There remains no consensus regarding the optimal management of Takotsubo cardiomyopathy. However, the use of beta-blockers should be considered empirically in the setting of tachycardia and persistent ST-segment elevation. In addition, anticoagulant therapy should be administered to prevent apical thrombus formation in the early period.

The authors state that they have no Conflict of Interest (COI).

\section{References}

1. Sato H, Tateishi H, Dote K, Uchida T, Ishihara M. Tako-tsubo-like left ventricular dysfunction due to multivessel coronary spasm. In: Clinical Aspect of Myocardial Injury: from Ischemia to Heart Failure. Kodama K, Haze K, Hori M, Eds. Kagakuhyoronsha Publishing Co., Tokyo, 1990: 56-64 (in Japanese).

2. Kurisu S, Sato H, Kawagoe T, et al. Tako-tsubo-like left ventricular dysfunction with ST-segment elevation: a novel cardiac syndrome mimicking acute myocardial infarction. Am Heart J 143: 448-455, 2002.

3. Sharkey SW, Windenburg DC, Lesser JR, et al. Natural history and expansive clinical profile of stress (tako-tsubo) cardiomyopathy. J Am Coll Cardiol 55: 333-341, 2010.

4. Kamada T, Hayashi M, Yokoi H, et al. Takotsubo cardiomyopathy with involvement of delayed-onset rhabdomyolysis and acute kidney injury after rosuvastatin treatment. Intern Med 54: 31-35, 2015.

5. Ogura R, Hiasa Y, Takahashi T, et al. Specific findings of the standard 12-lead ECG in patients with 'Takotsubo' cardiomyopathy: comparison with the findings of acute anterior myocardial infarction. Circ J 67: 687-690, 2003.

6. Kosuge M, Ebina T, Hibi K, et al. Simple and accurate electrocardiographic criteria to differentiate takotsubo cardiomyopathy from 
Intern Med 54: 1-2, 2015 DOI: 10.2169/internalmedicine.54.3454

anterior acute myocardial infarction. J Am Coll Cardiol 55: 25142516, 2010.

7. Kumar S, Kaushik S, Nautiyal A, et al. Cardiac rupture in takotsubo cardiomyopathy: a systematic review. Clin Cardiol 34: 672-
676, 2011.

8. Kurisu S, Inoue I. Cardiac rupture in tako-tsubo cardiomyopathy with persistent ST-segment elevation. Int J Cardiol 158: e5-e6, 2012.

(C) 2015 The Japanese Society of Internal Medicine http://www.naika.or.jp/imonline/index.html 